\title{
Cien años de SOledad: LA INCONSTITUCIONALIDAD POR OMISIÓN*
}

\author{
Patricia Estévez Huebra, Laura Gallego Herráez, Daniel González Herrera, \\ Walter Reifarth Muñoz, José Román Martín, Elena Sánchez Carrero, \\ Álvaro Sánchez González, Diego Sastre García, Ángel Luis Torres Díaz.
}

\section{RESUMEN}

Con el presente trabajo, elaborado en el seno del Semillero de Investigación de Derecho Procesal de la Universidad de Salamanca, pretendemos dar una visión profunda e integradora de las omisiones inconstitucionales y sus perversas consecuencias sobre la protección efectiva de los derechos fundamentales, así como una posible solución procesal a partir de los instrumentos que nos permite el Derecho Comparado.

La deliberada abstracción de las constituciones de nuestro tiempo y la libertad de configuración del legislador pueden desencadenar problemas de difícil solución jurídica. En efecto, a lo largo del trabajo no hemos querido perder de vista la relativa eficacia del control jurisdiccional de los silencios legislativos. Ello no significa que nosotros, como juristas, no tengamos el interés (y la obligación) de buscar una solución práctica. Solución de deberá mediar entre el respeto al principio de separación de poderes y la viabilidad fáctica de un sistema garantista de nuestros derechos.

Palabras clave: Omisión inconstitucional, silencio legislativo, justicia constitucional, inacción, actividad legislativa.

* Este trabajo surge del semillero de investigación creado en el seno del Departamento de Derecho Procesal de la Universidad de Salamanca y dirigido por el profesor Dr. D. Lorenzo M. Bujosa Vadell, Catedrático de Derecho Procesal. Se presentó los días 12,13 y 14 de septiembre de 2012, en Cartagena de Indias (Colombia), por Walter Reifarth Muñoz (reifarth@usal.es) en el marco del XXXIII Congreso Colombiano de Derecho Procesal, resultando el trabajo que obtuvo el Primer Premio del XIII Concurso Internacional para Estudiantes de Derecho Nivel Pregrado, con el tema "Las sentencias que dictan las cortes constitucionales". 


\begin{abstract}
In this essay, developed within the research group of Procedural Law of the University of Salamanca, we aim to give a deep and conciliatory analyze of unconstitutional omissions and its perverse consequences on the effective protection of fundamental rights and a possible procedural solution from instruments that comparative law allows us.

The deliberate abstraction of the constitutions of our time and legislator configuration freedom can entail problems with a difficult legal solution. Indeed, throughout the essay we do not forget the relative efficacy of judicial review of legislative silence. It does not prevent us, as jurists, to have the interest (and the obligation) to find a practical solution. Solution must be between the respect for the principle of separation of powers and the factual viability of a guarantor system of our rights.
\end{abstract}

Key words: unconstitutional omission, legislative silence, constitutional justice, inactivity, legislative activity.

\title{
INTRODUCCIÓN
}

En una de sus obras más conocidas, Montesquieu afirma que "no existe tiranía peor que la ejercida a la sombra de las leyes y con apariencias de justicia”. Aunque es indudable que ha pasado mucho tiempo y que la conjunción de derecho y poder político se nutre de otras ideas, no podemos negar el buen criterio del filósofo al escribir estas líneas.

La aceptación casi universal del constitucionalismo moderno se ha visto influida, entre otros factores, por la limitación del poder como idea-fuerza y por la viabilidad "extremadamente práctica" de un conjunto de compromisos sociales, económicos y políticos que ésta asume ${ }^{1}$. Aunque axiológicamente las constituciones no tengan rivales, su condición no es por ello mucho más confortable. Esto quizá encuentre alguna clave explicativa si se parte del supuesto de que en la historia constitucional han jugado dos factores, en el fondo no tan afines: la necesaria abstracción de los preceptos contenidos en la Norma Fundamental, de un lado, y la eficacia directa como superior garantía frente a los excesos de poder, de otro.

1 DUNN, J. Democracia: el viaje inacabado (508 a.C.-1993), dir. J. Dunn, Tusquets editores, 1995, p. 299. Al introducir aquí la expresión "constitucionalismo moderno", nos referimos al nacimiento del Estado constitucional tal como lo entendemos hoy día, en el que los poderes se articulan bajo una forma de organización que pretende la sujeción de todas las magistraturas del Estado a la Constitución, que se eleva a rango de norma jurídica superior. Anteriormente el Estado Constitucional se identificaba sencillamente con la separación de poderes; ahora, la Constitución es algo más, es una norma jurídica que dispone la sujeción de todo poder a sus propios preceptos y, por lo que nos interesa, señala la sujeción del legislador al derecho. Así, la concepción kelseniana del ordenamiento jurídico se plasma con toda evidencia. 
Y es precisamente en esta última dicotomía donde tienen su campo de acción los tribunales constitucionales. El alcance de sus sentencias, aún reconociendo su incalculable valor transversal, sigue siendo aún objeto de estudio.

Pocos elementos novedosos se pueden aportar sobre la importancia y ventajas de la concreción de la Constitución. Porque ésta no solo está en las grandes discusiones doctrinales, sino sobre todo en la vida que se desenvuelve en los hospitales, las escuelas, las viviendas, es decir, allí donde estamos juntos. Allí donde la persona de carne y hueso coincide con otras en una práctica conformada por el poder político, el derecho y la cultura.

Nunca sobran las sensatas apelaciones a la «modestia de oficio». Reconocer los límites del método y el conocimiento jurídico debe partir ciertamente de una sana perplejidad de los autores ante las demandas que se suscitan en este campo. No está en nuestro ánimo entrar en la bondad de un cierto modelo político, aún cuando el trabajo se preste a ello. Todo lo más, pretendemos ofrecer una crítica razonada y constructiva, ofreciendo nuestra propia solución al problema en cuestión.

\section{LA INCONSTITUCIONALIDAD POR OMISIÓN EN EL MARCO DEL DERECHO COMPARADO}

La escasa -pero exponencialmente creciente- literatura jurídica sobre este tema nos obliga a dedicar buena parte del presente trabajo a definir la inconstitucionalidad por omisión, sus clases y las bases teóricas necesarias para el posterior estudio de los remedios procesales en la materia.

\subsection{Concepto y naturaleza jurídica}

La Constitución, por sus propias funciones y características, no puede agotar todas las instituciones que recoge, por lo que hace necesaria la actuación ulterior del legislador. Es esta necesidad la que da origen a la figura jurídica de la inconstitucionalidad por omisión, que entendemos como asignatura pendiente en el marco del derecho constitucional comparado.

Los estudios sobre esta figura pueden contemplarse desde dos perspectivas distintas, atendiendo al alcance de su concepto. En un sentido amplio, esta figura no solo se produce por la inacción de los deberes que la Constitución encomienda al poder legislativo, sino también por la inactividad del resto de poderes constituidos. Esta tesis es defendida por autores como V. Bazán², G. J. Bidart Campos³, N. P.

2 BAZÁN, V. Propuestas normativas y jurisdiccionales frente a las omisiones inconstitucionales, en CARBONELL, M. (coord.), En busca de las normas ausentes..., cit, nota 12, pp. 117 y 118.

3 BIDART CAMPOS, G. J. La justicia constitucional y la inconstitucionalidad por omisión, Anuario Jurídico, México, núm. VI, 1975. 
Sagüés ${ }^{4}$ o F. Fernández Segado 5 . Por otro lado, en un sentido estricto, la inconstitucionalidad por omisión únicamente se refiere a la inacción de la función legislativa en el dictado de la norma que la Constitución le impone. Entre los juristas que sustentan esta postura se encuentran J. J. Fernández Rodríguez ${ }^{6}$, I. Villaverde Menéndez $\mathrm{o}$ J. J. Gomes Canotilho ${ }^{8}$.

La distinción que hemos considerado conveniente incluir aquí no es baladí, ya que de ella dependerá en buena medida el desarrollo posterior del trabajo y, en general, el alcance de las sentencias que las cortes constitucionales pueden dictar sobre el tema. Dadas las posturas reseñadas y ante la brevedad del trabajo que impide detenernos en consideraciones epistemológicas o de mayor amplitud, abrazaremos el concepto restringido de inconstitucionalidad por omisión. En virtud del mismo, la omisión inconstitucional hace referencia a la inactividad del legislador, durante un tiempo razonablemente prolongado, en aquellos encargos (implícitos o explícitos) dispuestos en la Ley Básica y que a él le son propios, de forma que se impide la eficaz aplicación de los preceptos constitucionales.

Como señala I. Villaverde, la omisión inconstitucional solo tiene sentido "cuando la norma constitucional [...] ha decidido que determinada realidad se configure jurídicamente de cierta forma y el legislador con su silencio crea situaciones contrarias a lo querido por el soberano". Se trata, pues, de un silencio del legislador, fundamentado en la asimetría natural de poderes endógena al principio democrático, que desplaza al Pueblo soberano y se convierte en poder constituyente, alterando con ello el contenido normativo de la Constitución.

$4 \quad$ SAGÜES, N. P. "Inconstitucionalidad por omisión de los poderes Legislativo y Ejecutivo. "Su control judicial". Ius et Veritas. Revista de la Facultad de Derecho de la Pontificia Universidad Católica del Perú, Lima, núm. 5. Del mismo autor, "Instrumentos de justicia constitucional frente a la inconstitucionalidad por omisión”, en VEGA GÓMEZ, J. y CORZO SOSA, E. (coord.), Instrumentos de tutela y justicia constitucional..., nota 11, pp. 605 y ss.

5 FERNÁNDEZ SEGADO, F. "La dinamización de los mecanismos de garantía de los derechos y los intereses difusos en el Estado social", Boletín Mexicano de Derecho Comparado, México, año XXVIII, núm. 83, mayo-agosto de 1995, p. 598.

6 FERNÁNDEZ RODRÍGUEZ, J. La inconstitucionalidad por omisión..., cit., nota 12. pp. 74 y ss.

7 VILLAVERDE MENÉNDEZ, I. "La inconstitucionalidad por omisión. Un nuevo reto para la justicia constitucional”, en CARBONELL, M. (coord.), En Busca de las normas ausentes..., Op. cit. nota 12, p. 72 .

8 Citado por IBAGÓN, M. “Control constitucional de las omisiones legislativas en Colombia”, en VEGA GÓMEZ, J. y CORZO SOSA, E. (coord.), Instrumentos de tutela y justicia constitucional..., Op. cit., nota 11, p. 313.

9 VILLAVERDE, I., La inconstitucionalidad por omisión, nota 5, pp. 3-4, MacGraw-Hill, Madrid, 1997. 


\subsection{Tipos de omisión inconstitucional}

Las omisiones inconstitucionales hacen referencia al incumplimiento por parte legislador de su deber de legislar expresamente señalado en la Constitución. Como hemos visto, no se trata simplemente de un no hacer, sino en un no hacer algo normativamente predeterminado.

Condición esencial de este silencio es el deber jurídico de legislar respecto del cual la conducta pasiva del legislador resulta constitucionalmente incompatible. En este sentido, la abstención constituye una infracción de un precepto constitucional, lo que diferencia la omisión inconstitucional de otros tipos de silencios legislativos amparados por la tarea de dirección política de los representantes.

Con efectos sistemáticos, y con el objetivo de profundizar sobre la naturaleza jurídica diferenciada, distinguimos dos tipos de omisiones inconstitucionales: las absolutas y las relativas. En las primeras, el incumplimiento por parte del legislador de la obligación constitucional de expedir una regulación específica constituye una total inactividad por parte del Parlamento y, por ende, supone la ausencia total de un texto o precepto legal ejecutivo de la Constitución. Por otro lado, las omisiones inconstitucionales relativas suponen una actividad legislativa, pero insuficiente o defectuosa, es decir, el legislador regulará una situación determinada omitiendo o dejando de lado supuestos de hecho que al momento de aplicarse el precepto correspondiente genere tratamientos inequitativos que vulneran el principio de igualdad constitucionalizado.

\subsection{Constitución abierta y Constitución dirigente}

Tenemos que dar cuenta de que la Constitución es una verdadera norma jurídica y no únicamente un conjunto de principios programáticos. Del mismo modo, es preciso concretar la doble perspectiva de la norma normarum, que explicamos a continuación. Señalar estas características se hace necesario para entender la dinámica del proceso constitucional moderno y trasladarla al instituto objeto de este trabajo.

El carácter abierto de la Constitución implica configurar un sistema que permita, como se ha señalado repetidamente, el libre acceso de todos al proceso político y a los instrumentos del cambio político, es decir, la admisión como esencial de distintas opciones políticas y de la hipótesis de una revocación futura de las decisiones actuales. Ello implica dotar de una mayor flexibilidad al diseño de las políticas públicas y que sean las generaciones futuras a través de sus representantes en el órgano legislativo los que decidan cómo concretar el contenido constitucional.

Por otro lado, por Constitución dirigente debemos entender la plasmación, al máximo nivel normativo, de un programa de actuación futura que tiene que ser 
llevado a cabo por los poderes constituidos y así llegar a una sociedad más avanzada bajo la inspiración del principio de igualdad material.

Solo desde esta doble perspectiva de las constituciones actuales podremos entender mejor la problemática de esta materia.

\subsection{Dificultades en su estudio}

La temática que en el presente trabajo se aborda es de una naturaleza opaca, de enorme complejidad y de perfiles difusos. A continuación, haremos un breve estudio de cada una de las circunstancias que, a nuestro juicio, creemos que dificultan su análisis.

Se habla habitualmente, al nombrar este tema en España, del problema que plantea la posible interferencia de la justicia constitucional en los tres poderes clásicos del Estado: legislativo, ejecutivo y judicial. Pero, ¿qué interferencia hay cuando lo que se plantea es que sea el Tribunal Constitucional el que controle los actos del poder legislativo? ¿Pertenece por ello el Tribunal Constitucional al poder judicial? La respuesta es ciertamente negativa: el Tribunal Constitucional no forma parte de la planta judicial, puesto que es garante del cumplimiento de la Constitución, función atribuida por cualquier Constitución en un sistema de justicia constitucional concentrada. En este plano jurisdiccional, tiene sentido que sea el Tribunal Constitucional, y no otro, el que mande desarrollar los preceptos constitucionales. $\mathrm{Y}$ es aquí donde cobra todo su sentido la célebre afirmación kelseniana de que los órganos de justicia constitucional en modelos concentrados son "legisladores negativos"10.

Otro problema que se nos plantea al adentrarnos en el estudio de la cuestión que nos atañe es la falta de jurisprudencia. Son pocos aquellos Estados que tienen una sólida tradición jurisprudencial sobre este tema; y aún inferior es el número de constituciones que recogen explícitamente dicha posibilidad o figura. Como corolario, la gran mayoría de los centros de justicia constitucional, por la sujeción estricta a las funciones otorgadas por sus respectivas leyes básicas, no se han atrevido a desarrollar una importante labor jurisprudencial al respecto.

Un problema adicional en el estudio y comprensión de este instituto es la incorrección política, tema que exige todas las cautelas. El hecho de controlar la actuación política del legislador es un tema complicado en cualquier país, ya que corresponde a este la dinámica del impulso político llevado a cabo por el poder ejecutivo. Esta libertad, justificada en cualquier Estado regido por el principio democrático, no debe quebrar y convertirse en la arbitrariedad más absoluta, carente de cobertura normativa idónea y, por ello, un comportamiento no deseado en

10 KELSEN, Hans, ¿Quién debe ser el defensor de la Constitución?, Editorial Tecnos, 2a edición, Madrid, 1999. 
el Estado social y democrático de Derecho. Y este comportamiento está agravado por la responsabilidad política, que se destila en el Parlamento y que permite el desarrollo de un sistema que solo encadene sanción para su producto, la ley, que es expulsada del ordenamiento jurídico.

En el caso de producirse una omisión inconstitucional, la rigidez de la ley constitucional hace que, mientras el legislador no modifique su contenido por el cauce debido, la ley siga sometida a los límites y mandatos que aquélla impone.

Aunque hay cierto sector de la doctrina que niega la existencia de este instituto de forma tajante ${ }^{11}$, lo más habitual es que ese rechazo se presente como un cierto escepticismo respecto de la eficacia del control sobre los silencios del legislador. Una prueba evidente de ese rechazo es precisamente el hecho de que muchos manuales sobre justicia constitucional no hagan mención explícita al problema. De hecho se trata de una materia con un escaso trato doctrinal, lo que dificulta dar respuestas certeras a este fenómeno, abriendo el abanico a un mayor número de interpretaciones. Ni siquiera puede encontrarse entre la doctrina y la jurisprudencia un concepto global e inequívoco del fenómeno de la inconstitucionalidad por omisión ${ }^{12}$.

Los problemas conceptuales suponen otra piedra en el camino cuando pretendemos hacer un estudio detallado de la inconstitucionalidad por omisión. La falta de categorías en la legislación positiva refuerza la ya de por sí la complejidad conceptual del tema, al igual que la existencia de elementos comunes con otras categorías normativas similares. Por ello, hemos considerado dedicar un esfuerzo importante en concretar las definiciones empleadas en este trabajo para que el estudio resulte clarificador y poder llegar al pleno entendimiento de la cuestión suscitada.

De entre todos los conceptos jurídicos, el que presenta mayor facilidad de confusión con la institución estudiada es el de la laguna o vacío normativo ${ }^{13}$. No debemos confundirlos: en el caso de la inconstitucionalidad por omisión existe un mandato expreso del legislador constitucional que no hay en el supuesto de la laguna.

11 Tal es el caso del profesor PÉREZ ROYO, J. quien ha afirmado en multitud de ocasiones que la inconstitucionalidad por omisión no existe. Así lo manifestado, entre otras, en su trabajo Inconstitucionalidad Por Omisión. Temas Básicos de Derecho Constitucional. Madrid. Civitas. Vol. 3. 2001, pp. 66-68.

12 Véase el caso de Costa Rica, país en el que el fenómeno de la inconstitucionalidad por omisión no solo alude al silencio por parte del poder legislativo, sino que se confunde con el silencio administrativo; o de Hungría, donde esta figura también abarca el incumplimiento de obligaciones impuestas por normas infraconstitucionales.

13 Una laguna se produce cuando el sistema no prevé respuesta a un caso concreto, esto es, cuando un supuesto de hecho no tiene asignado en el sistema una consecuencia jurídica. 


\subsection{Argumentos a favor}

Dada la compleja polémica que hay en torno al instituto de la inconstitucionalidad por omisión, se hace inevitable detallar los argumentos más importantes que se pueden esgrimir a favor de su existencia.

Ya en su Teoría pura del Derecho ${ }^{14}$, Hans Kelsen adelantaba que es el carácter coercitivo de los mandatos normativos el que diferencia al Derecho de otras reglas vigentes en el seno de una sociedad; o dicho de otra forma, la naturaleza jurídica de una norma sólo es predicable cuando, ante el incumplimiento de la misma, se responde con una sanción.

Partiendo de lo anterior, sería difícilmente justificable la inexistencia del instituto de la inconstitucionalidad por omisión, en tanto la finalidad del mismo no es otra que sancionar la vulneración de un mandato constitucional. Negar la necesidad de esta figura sería tanto como negar la eficacia normativa de la Carta Magna, otorgando a sus preceptos el carácter de meros principios programáticos, carentes de fuerza vinculante, algo contra lo que el Tribunal Constitucional español ya se ha pronunciado en reiterada jurisprudencia ${ }^{15}$.

Asimismo, el hecho de que el ordenamiento jurídico no arbitrase mecanismos de sanción ante las infracciones de la Norma Suprema pondría en jaque la supremacía que sobre las restantes normas e instituciones ostenta el texto constitucional. Esta supremacía, consagrada en nuestro caso en el art. 9.3 de la Constitución Española, implica el sometimiento que a la misma deben los diferentes poderes del Estado en su actuación; sometimiento que no se estaría cumpliendo si ante la desobediencia por parte del Legislativo de un mandato constitucional no se estableciesen instrumentos jurídicos de reacción. El instituto de la inconstitucionalidad por omisión es, por tanto, consecuencia directa de la simple aplicación de la jerarquía normativa establecida en la propia Constitución. Por todo ello, parece irónico que cualquier ordenamiento que consagre la supremacía constitucional permita la impunidad de las infracciones de los mandatos contenidos en su texto, consintiendo que quede al arbitrio de un poder constituido -el Legislativo- el cumplimiento de los deberes impuestos por la norma a la que, desde un plano formal, debe obediencia.

Pero no sólo son la eficacia normativa de la Constitución y la supremacía que ésta ostenta los valores que se verían cuestionados ante la falta de un instituto como el analizado en el presente trabajo, sino también el «carácter abierto» inherente

14 KELSEN, H., Teoría Pura del Derecho, Porrúa, México, 1991, pp. 46.

15 Por todas, Sentencia del Tribunal Constitucional español 16/1992, de 28 de abril, fundamento jurídico primero: "Conviene no olvidar nunca que la Constitución, lejos de ser un mero catálogo de principios de no inmediata vinculación y de no inmediato cumplimiento hasta que sean objeto de desarrollo por vía legal, es una norma jurídica, la norma suprema de nuestro ordenamiento, y en cuanto tal, tanto los ciudadanos como los poderes públicos y, por consiguiente, también los jueces y magistrados integrantes del Poder Judicial, están sujetos a ella". 
a la idea de Constitución. Éste se traduce, como ya hemos escrito supra, en una formulación suficientemente amplia del texto constitucional; formulación que ha de posibilitar sucesivas reinterpretaciones, que habrán de concretarse en mandatos legislativos. Sólo así se puede garantizar la función transformadora de la sociedad que habitualmente se predica de la Constitución. Por tanto, el carácter abierto de la Norma Fundamental requiere, para poder mantenerse como tal, del auxilio legislativo. La inactividad del legislador, a quien el constituyente encarga esta labor actualizadora, da lugar a una petrificación del ordenamiento jurídico, en cuanto mantiene la incertidumbre acerca de cómo ha de ser entendida una determinada materia de relevancia constitucional. En consecuencia, la figura de la inconstitucionalidad por omisión se erige también como una forma de garantizar que la Constitución sea una norma de mínimos, al sancionar el incumplimiento de las obligaciones de desarrollo legislativo que la misma impone ${ }^{16}$.

Por último, no debe obviarse la incidencia que en el principio democrático tendría el hecho de que el incumplimiento de los mandatos constitucionales quedase impune; la Constitución, en cuanto manifestación de la voluntad del Pueblo Soberano, dota de unidad al ordenamiento jurídico, de tal forma que todo acto normativo -incluidos los silencios- que no respeten las reglas de validez establecidas en la misma no pueden ser identificados con dicha voluntad. En consecuencia, dotar de validez -o lo que es lo mismo, no sancionar- actos carentes de respaldo constitucional, identificándolos con la voluntad soberana, supone vaciar de contenido el principio democrático.

\section{LA SENTENCIA DE INCONSTITUCIONALIDAD POR OMISIÓN}

Hemos escrito ya sobre la importancia y los efectos perversos que la institución de la inconstitucionalidad por omisión tiene en el ordenamiento jurídico. En palabras de Karl Loewenstein, "el desprestigio de la Constitución, por inercia de órganos meramente constituidos, representa uno de los más graves aspectos de la patología constitucional, pues refleja un inaceptable desprecio [...] de la autoridad suprema a la Ley Fundamental del Estado"17.

Es evidente que los órganos llamados a hacer valer el principio de jerarquía normativa (los jueces, y en particular, los jueces constitucionales) también lo deben

16 La inexistencia de mecanismos de sanción ante la pasividad legislativa, o el funcionamiento deficiente de los mismos, podría llevar a que la desconfianza en que el legislador cumpla el mandato constitucional de regular una determinada materia fomentase la creación de Constituciones con mayor carga normativa; esto es, Constituciones que dejarían de ser normas de mínimos para pasar a ser normas de detalle. Se desnaturalizaría, por tanto, la esencia del texto constitucional, en tanto que el mismo no puede agotar la regulación de las materias que incluye.

17 LOEWENSTEIN, K., Teoría de la Constitución, Barcelona, Ariel, 1982, p. 222 
hacer entre la Constitución y la ley. Queda por ver qué remedios procesales existen, desde la óptica del Derecho Comparado y en modelos de justicia constitucional concentrada, para poner fin a un retraso injustificado del desarrollo ulterior de la Ley Básica. Las modalidades y efectos de las sentencias presentan una gran variedad, por lo que se hace necesario profundizar críticamente en las que consideramos más relevantes, de cara a establecer nuestra propuesta particular.

Partiremos de un sistema de control de constitucionalidad concentrado, en el que un órgano ostente el monopolio de la declaración de inconstitucionalidad de las leyes y sea catalogado como último intérprete de la Constitución. Asimismo, las exigencias del Estado social generan una obligación de desarrollo que pesa sobre el legislador, puesto que se sostiene que el Estado social y democrático de Derecho es un encargo al mismo. Consecuencia de lo anterior es que el legislador debe especificar la Norma Fundamental a través de la ley de manera que potencie su función en el marco del Estado social.

\subsection{Características generales de la sentencia}

Un estudio comparativo al detalle de las particularidades de las sentencias de inconstitucionalidad por omisión no sería posible en un trabajo forzosamente breve. Por ello, intentaremos analizar las características cruzadas que se repiten con más frecuencia en los estudios particulares de los órganos de justicia en cada ordenamiento jurídico. Sin embargo, para no perdernos en una abstracción infructífera, hemos considerado conveniente hacer referencia a ciertas regulaciones individuales.

\subsubsection{Control jurídico de los silencios legislativos}

La mayor dificultad del control jurisdiccional de los silencios legislativos resulta de las consecuencias que dicho control presenta para la determinación por el juez de las normas aplicables al caso. En concreto, si el silencio lo es del legislador y no de los preceptos de la ley, ante la duda del juez en la aplicación de la normativa deberá elevar cuestión de inconstitucionalidad.

Según C. Mortati, donde exista laguna el juez ordinario tiene facultades para integrarla haciendo uso de los mecanismos de que éste dispone ${ }^{18}$. Sin embargo, en caso de omisión legislativa, el juez tiene limitadas sus actuaciones puesto que su función le impide integrarla.

Con respecto a esos límites y al comportamiento del juez en estos supuestos, hay que tener en cuenta el tipo de silencio que debe afrontar en el juicio. Como hemos mencionado anteriormente, si el silencio no es de la ley, la inconstitucionalidad de su omisión, sometida a la condición de la inexistente interpretación alternativa de

18 MORTATI. C., Appunti per uno studio sui rimedi giurisdizionali contro comportamenti omissivi del legislatore, en la obra del propio autor (1972), "Problemi di Diritto pubblico nell'attuale esperienza costituzional repubblicana (Raccolta di Scritti-III”), Giuffrè, Milán, pp. 948 y ss. 
la ley omisiva que posibilite redimir su constitucionalidad obliga al juez ordinario, en caso de que estamos ante una ley posterior a la Ley Básica, a elevar la cuestión al juez constitucional, único cuya competencia le faculta para decidir sobre la validez o no de la ley, suprimirla del ordenamiento y colaborar en esa medida con el juez ordinario en la determinación del derecho aplicable al caso.

En relación a los preceptos constitucionales que proporcionan mandatos expresos al legislador (normas constitucionales imperativas), no quedan exentos de toda eficacia normativa cuando el legislador no haga uso del permiso o no cumpla con el mandato ${ }^{19}$.

Cosa distinta ocurre, a pesar de que el precepto constitucional contenga mandato dirigido al legislador, si la situación jurídica querida por la Constitución goza de eficacia directa sin depender de la mediación legislativa, por mucho que ésta sea debida y necesaria ${ }^{20}$.

La situación jurídica que debe existir sólo podrá ser la que derive de la aplicación directa de la Constitución; esta eficacia se impone como deber al juez, como consecuencia de su sometimiento a ella, de forma que si no actúa atendiendo a ese sometimiento, será el juez quien infrinja la Constitución, y no el silencio legislativo.

Por ello, la eficacia directa de la norma constitucional implica la imposición al juez de la situación jurídica como ella se define, sin atender a la ausencia de norma legal que modifique esa eficacia determinando el modo de existencia de semejante situación jurídica en el ordenamiento. Pues bien, es apreciable cómo el juez ordinario está vinculado a ese residuo de eficacia del precepto constitucional, en el caso de silencios legislativos ${ }^{21}$.

Es pertinente señalar que, si estamos ante una norma constitucional que goza de eficacia directa, no existe posibilidad jurídica de que exista norma implícita que le sea contraria.

Mención aparte merece un recurso que, por su objeto y naturaleza, es indudablemente un recurso de inconstitucionalidad por omisión, aunque sistemáticamente pueda dudarse de su inclusión aquí. Se trata de los llamados «recursos por omisión» o «por inactividad» que presentan algunas organizaciones internacionales de integración. En el caso particular de la Unión Europea, la organización de integración más acabada del mundo ${ }^{22}$, este recurso se prevé en el artículo 265 de su Tratado

\footnotetext{
19 Esto se pone de manifiesto en la STC 45/89 en su FJ $10^{\circ}$.

20 Se trata de normas constitucionales auto aplicativas o normas constitucionales abiertas al desarrollo legislativo o configuración legal.

21 Vid. "Secundum constitutionem", Revista del Centro de Estudios Constitucionales, núm. 13, 1992, pp. 9 y ss.

22 También existe este recurso, por ejemplo, en la Comunidad Andina, previsto en los artículos 129 a 134 del Estatuto del Tribunal de Justicia de la Comunidad Andina.
} 
de Funcionamiento. Su objeto es que el Tribunal de Justicia de esta organización declare que una Institución de la Unión se ha abstenido de adoptar una decisión a la que venía obligada en virtud de la Constitución material de la Unión, es decir, los Tratados sobre los que ésta se funda. La legitimación activa pertenece aquí a cualquier Estado miembro o a las propias instituciones. Asimismo, pueden interponerlo las personas físicas y jurídicas cuando consideren que no se les ha dirigido un acto destinado a ellas ${ }^{23}$.

\subsubsection{Interposición del recurso}

Con carácter general, dispondrán de legitimación para iniciar una acción contra una omisión inconstitucional las personas perjudicadas por ella, las consideradas víctimas de dicha situación. Ahora bien, todo ello está ampliamente matizado en las legislaciones de algunos de los Estados que contemplan esta figura, por mencionar algún ejemplo, citaremos los siguientes:

En Costa Rica la acción de inconstitucionalidad por omisión sólo puede interponerse si no cabe la presentación del recurso de habeas corpus o del de amparo (recursos más efectivos y rápidos). Determinados sujetos tampoco necesitan la existencia de un caso previo para plantear la acción de inconstitucionalidad (es decir, pueden plantear un control abstracto); entre ellos el Defensor de los Habitantes y el Fiscal General de la República.

En Hungría este procedimiento puede incoarlo el Tribunal Constitucional de oficio o a iniciativa de cualquiera.

En Angola están legitimados el Presidente de la República, un quinto de los diputados y el Fiscal General del Estado.

Por lo que respecta a Brasil, la legitimación activa la posen el Presidente de la República, la Mesa del Senado Federal, la Mesa de a la Cámara de los Diputados, la Mesa de una Asamblea Legislativa, el Gobernador de un Estado, el Procurador General de la República, el Consejo Federal de la Orden de los Abogados del Brasil, un partido político con representación en el Congreso y una confederación sindical o entidad de clase de ámbito nacional (art. 103. I, II III, IV, V, VI, VII, VIII, IX, respectivamente de la Constitución de Brasil).

Además, tiene legitimación activa todo aquel brasileño o extranjero residente en Brasil, sea persona natural o jurídica, al que la falta de desarrollo de un precepto le imposibilite ejercitar un derecho o libertad constitucional. Una vez mostrados estos casos vemos que el panorama ofrecido es muchísimo más rico y complejo que lo señalado de forma genérica, teniendo, por tanto, que poner especial atención y cuidado a la hora de manejar estas normativas.

${ }^{23}$ Cf. MANGAS MARTÍN, A. y LIÑÁN NOGUERAS, D. J., Instituciones y Derecho de la Unión Europea, 6 ${ }^{\mathrm{a}}$ Ed., Madrid, Tecnos, 2010, p. 454. 
Es necesario, asimismo, tratar separada y pormenorizadamente el recurso de amparo y su relación con la omisión. Dicho recurso suele ser recurrente ante una situación de inconstitucionalidad por omisión, lo que no queda claro es cuál es el verdadero papel que juega en la institución que estamos analizando. Para ello volveremos a acercarnos a las legislaciones estatales para ver como abordan el problema o cuál es el enfoque que ofrecen al respecto.

En Costa Rica la acción de inconstitucionalidad por omisión sólo puede interponerse si no cabe la interposición del recurso de habeas corpus o el de amparo (recursos más efectivos y rápidos, como ya hemos señalado).

En Argentina, en el terreno positivo de la inconstitucionalidad por omisión, la acción de amparo no puede considerarse como el mecanismo instaurador de este instituto. Este hecho no implica, empero, que a nivel doctrinal no se contemple, en autores como Bidart Campos y Vanossi.

La acción de amparo puede accionarse ante la omisión de quien debe ejecutar un acto concreto y contra quien debe pronunciar una decisión y no la dicta. El problema radica en determinar, vía interpretativa, si es accionable ante la omisión legislativa, lo cual no deja de ser una actitud audaz en ciertos ambientes jurídicopolíticos. La cuestión de la mora del Congreso ha llegado en alguna ocasión, a través de la acción de amparo, a la Corte Suprema, supuestos que no acarrearon mayores consecuencias al entender el Tribunal que no era censurable la tardanza del Congreso al no tener el deber de proceder inmediatamente a la concreción de los preceptos constitucionales. En cambio, en algún caso, si se ha admitido la acción de amparo contra inacciones del Poder Ejecutivo. Esta situación ha despertado críticas en la doctrina, que ha señalado que las inconstitucionalidades por omisión son, en el fondo, tan graves como las inconstitucionalidades por acción.

El caso alemán nace de una evolución en la que se que pasa de contemplar el recurso de amparo como mecanismo de esta institución solo a nivel doctrinal, con las aportaciones de Seiwerth, con su admisión del recurso de amparo frente a las infracciones de derechos fundamentales del legislador por omisión, y PINGER, a su aceptación con la jurisprudencia generada en el Tribunal Constitucional a raíz de la sentencia 26/1969, de 29 de enero.

Tras estos breves apuntes, tanto legislativos como doctrinales de estos países, podemos intentar resumir en una frase cual es la función desempeñada por el recurso de amparo, es decir, el mecanismo que pone en marcha todo el funcionamiento, todo el engranaje de la inconstitucionalidad por omisión. ${ }^{24}$

24 Es oportuno señalar que en algunos países tales como Italia o Brasil no recogen la figura del recurso de amparo en la normativa reguladora de esta institución. 


\subsubsection{La reserva de ley: límite genérico a la integración judicial de omisiones inconstitucionales}

A diferencia del control realizado por el juez constitucional, el objeto de la resolución que debe dictar el juez ordinario no tratará sobre la validez de la norma implícita o expresa, toda vez que precisamente la determinación del derecho aplicable al caso, para aquello que es de su competencia, es una actuación previa a la resolución del caso sometido a su conocimiento, que es lo que su fallo expresará ${ }^{25}$. De ello se deriva la importancia de una reserva de ley sobre la materia objeto de conocimiento judicial, porque ésta establece límites a la acción judicial con respecto a la determinación del derecho aplicable, la reserva establece que el derecho aplicable a esa materia sólo pueda ser aquel que tenga rango de ley ${ }^{26}$.

La aplicación directa de la norma constitucional para la resolución del supuesto atendiendo a la norma implícita derivada del silencio y no contraria a la Constitución no genera dificultades. En cambio, si el juez llega a la conclusión de que esa norma implícita contradice a la Constitución, ello elimina el margen de actuación de los poderes públicos que han sido motivo de impugnación ante él. Su juicio sobre la norma a aplicar genera una laguna axiológica, posicionándole en la misma situación que si hubiera identificado ese vacío desde el inicio (laguna legal).

Existe la posibilidad de que dicha laguna pueda ser integrada en la forma que cada ordenamiento prevea. En el caso español, se establece en el artículo 1 del Código Civil (norma supletoria en esta materia, art. 4.6 del Código Civil) que a falta de ley (que aquí se entiende como enunciado normativo sea cual sea su rango), será aplicable la costumbre, y a falta de ésta los principios generales del derecho ${ }^{27}$.

\subsection{Efectos de las sentencias}

En el caso particular del ordenamiento jurídico español, consideramos que el fallo de las sentencias parcialmente desestimatorias es el más adecuado para declarar la inconstitucionalidad por omisión de la ley. Este fallo despliega sus efectos erga omnes y produce el efecto de cosa juzgada. No obstante, este último efecto no impide replantear la cuestión de inconstitucionalidad por omisión si surgen nuevas dudas

25 La función legislador en los casos en que la norma constitucional goza de eficacia directa, a pesar de que no excluye la intervención legislativa, es la de concretar en cada sector del ordenamiento jurídico la eficacia de la norma constitucional ante la que nos encontremos.

26 La presencia de reserva no implica la imposibilidad de resolver por el juez, sino únicamente una limitación a lo que pueda establecer en su fallo.

27 Otra forma de acudir a la Constitución para extraer de sus principios y valores la norma aplicable, para poder considerar que el fallo está "fundado en derecho" (artículo 248 de la LOPJ, artículo 372.3 de la LEC, artículo 142.4 LECr, para el orden contencioso administrativo la LEC por remisión de la D.A. $6^{a}$ de la LJCA, y el art 97.2 de la LPL y también la LEC por remisión de la D.A. 1'. LPL). 
sobre la interpretación de esa norma, siempre que, evidentemente, nos encontremos ante una omisión relativa.

Resulta sorprendente que la formalización de una declaración de inconstitucionalidad por omisión de una ley estribe en una sentencia desestimatoria, es decir, una resolución que desestima el vicio de inconstitucionalidad de la ley impugnada. Es en los fundamentos jurídicos de la sentencia, que no en su fallo, en los que el juez invalida formalmente la norma contraria a la Constitución, así como el cambio en la interpretación de la misma. De esta forma, todos los poderes públicos quedan vinculados a la doctrina establecida por el juez en su sentencia, donde estima la inconstitucionalidad de la norma implícita derivada del silencio de la ley.

Como hemos expuesto, el fallo desestimatorio produce efectos erga omnes, lo que no impide que puedan revisarse otras interpretaciones que sí podían anudar la inconstitucionalidad a ese enunciado legal que las soporta y que en otra ocasión se estimó constitucional ${ }^{28}$.

Aunque es cierto que no cabe declarar la nulidad formal de la norma implícita, porque lo impugnado es el enunciado legal que la incluye en su silencio, y por tanto, la nulidad formal afectaría a éste, esto no significa que las situaciones jurídicas provocadas por la norma implícita no sean revisables.

$\mathrm{Su}$ inconstitucionalidad afecta a su validez como norma, no a un simple cambio de circunstancias que la convierten a partir de ese momento en inválida, ya que desde su nacimiento crea una situación jurídica incompatible con la Constitución. Es por ello que la estimación de la inconstitucionalidad de la norma implícita que, como se ha indicado, se encuentra en los fundamentos jurídicos de la sentencia, tiene efectos retroactivos, sin perjuicio de que en los casos en los cuales las sentencias declaratorias de inconstitucionalidad de leyes, disposiciones o actos con fuerza de ley no se permitirán revisar procesos fenecidos mediante sentencias con fuerza de cosa juzgada, como así se establece en el artículo 40.1 de la Ley Orgánica del Tribunal Constitucional español.

Existe la posibilidad de que una vez invalidada la norma contraria a la Constitución, pueda el juez constitucional emitir una sentencia que desestime solo parcialmente parte de dicha norma y que indique cual ha de ser la interpretación adecuada de esa parte en concreto, e incluso, el juez constitucional tiene la facultad de proceder a una interpretación extensiva, así como analógica, para llenar la laguna que tiene lugar con la declaración de inconstitucionalidad. Sin que todo ello pueda considerarse una extralimitación en las funciones del juez constitucional.

28 Como señala I. VILLAVERDE, las sentencias desestimatorias, y las que la sigan, dicen que una ley es aún constitucional. El que pueda declararse después inconstitucional depende de la prueba de que en efecto había un motivo que así lo demuestra y que no fue esgrimido con anterioridad, y no de la simple voluntad del juez constitucional. 


\title{
2.3 La impugnación de la decisión del juez sobre el derecho aplicable ante un silencio legislativo
}

Se entiende que el juez ordinario infringe la Constitución si interpreta el silencio legislativo de forma contraria a ésta. Esta circunstancia existe siempre que sea posible interpretar el silencio con una norma implícita no contraria a la Constitución. Además, el juez debe optar por la interpretación más favorable a la constitucionalidad de las consecuencias jurídicas del silencio legislativo.

El juez ordinario es el único competente para escoger el derecho aplicable, siendo necesario que su selección motive su decisión y no es certero que pueda concebirse como fundada esa selección arbitraria. Con ella puede provocar la lesión de algunos de los derechos fundamentales garantizados en la Constitución Española, como el derecho a la tutela judicial efectiva.

El planteamiento de esta tesis y su consecuente impugnación ha generado controversia. El TC ha considerado siempre que se trataba de un asunto de mera legalidad ordinaria en la selección de normas aplicables, competencia exclusiva de tribunales y jueces (art.117.3 CE). A pesar de ello, el TC ha matizado al respecto señalando que esa selección debe hacerse dentro de la normativa que permita convenir el carácter motivado de la resolución (artículo 120.3 CE).

La decisión judicial se encontrará fundamentada en derecho, si la selección normativa aplicable no es errónea ni arbitraria.

A este respecto, es pertinente señalar el contenido de la STC 126/94:

\begin{abstract}
"Conforme este tribunal ha tenido ocasión de reiterar, la selección e interpretación de la norma aplicable corresponde en exclusiva a los órganos judiciales [...]. Sin embargo, este principio general admite excepciones, pues «el control por parte del Tribunal de la selección de la norma aplicable llevada a cabo por los órganos jurisdiccionales... podrá producirse si se ha tratado de una selección arbitraria, manifiestamente irrazonable; o ha sido fruto de un error patente; si se ha desconocido o no se ha tenido en cuenta por el juez la ordenación constitucional y legal de los controles normativos (arts. 160.1 y $163 \mathrm{CE}$ )... O en fin, si de dicha selección se ha seguido daño para otro derecho fundamental distinto al de la tutela judicial efectiva e igualmente tutelado a través del recurso de amparo» (STC 233/91)” (FJ 5º).
\end{abstract}

Para añadir en el fundamento 60: "Ahora bien, a efectos del canon del artículo 24.1 CE, la cuestión no es nunca desde un punto de vista material, la de mayor o menor corrección en la interpretación de la legalidad, o en la selección de la norma aplicable. Por el contrario, el criterio sólo puede situarse, so pena de afectar al propio ámbito del recurso de amparo constitucional, en el terreno de la arbitrariedad o manifiesta irrazonabilidad".

Se aprecia que no resulta del todo incorrecto el matiz en la impugnación de la selección judicial de la normativa aplicable siempre que se lesione un derecho 
fundamental ${ }^{29}$. El aspecto que genera más controversia, es el hecho de que exista la posibilidad de impugnar la decisión alegando no sólo que se ha vulnerado un derecho fundamental distinto a la tutela judicial efectiva, sino esa misma decisión, al carecer de un fundamento en derecho por haberse realizado de forma arbitraria la selección de la normativa aplicable incurriendo en un error patente o sin respetar el sistema de fuentes.

A pesar de esta crítica, se mantiene la afirmación de que la selección desvinculada del sistema de fuentes viola la tutela judicial efectiva ${ }^{30}$.

En conclusión, se puede afirmar que el hecho de que el juez opte por hacer uso de la analogía no implica necesariamente la vulneración de la tutela judicial efectiva o de otros derechos fundamentales, excepto el principio de igualdad con respecto a las omisiones relativas inconstitucionales.

Hay que señalar que la analogía es un instrumento de obligada utilización en el ordenamiento español, siempre que se cumplan las condiciones del artículo 4.1 del Código Civil, cuya consideración es asunto judicial; y el análisis sobre el acierto en ello es competencia, a priori, de la mera legalidad ordinaria. Por ello, el TC estará facultado para enjuiciar tal valoración judicial, sin perjuicio de que pueda hacer uso de la analogía, teniendo en cuenta el límite de reserva de ley, para resolver la cuestión que ante él se plantea.

La utilización de dicho instrumento, tendrá como objetivo restablecer el derecho vulnerado en caso de estimación del recurso de amparo, pero nunca suplir la apreciación judicial sobre su empleo.

\subsection{La determinación del "plazo razonable"}

Al definir más arriba la figura de la inconstitucionalidad por omisión, señalábamos como requisito esencial, entre otros, la inacción del legislador durante un tiempo razonablemente prolongado en los encargos que la Constitución le impone. Creemos estar ya en disposición de desarrollar este concepto jurídico indeterminado. $\mathrm{Y}$ hemos considerado conveniente analizarlo de manera separada a las sentencias, como elemento merecedor de especial atención, pero sin perder de vista que forma parte de un mismo todo.

¿Cuál es el lapso temporal que debe transcurrir sin que el legislador actúe para que podamos hablar de una omisión inconstitucional? La respuesta está cargada de toda polémica, puesto que tanto la doctrina como la jurisprudencia han adoptado respuestas muy diferentes. Y la resolución del conflicto no puede hacerse por me-

29 BORRAJO et al, hacen alusión a lo afirmado en sentencias como las SSTC 23/88, FJ 1º 126/94, FJ $5^{\circ} ; 22 / 94$, FJ $2^{\circ}$ ).

30 Vid. La obra colectiva de BORRAJO INIESTA/DÍEZ PICAZO GIMÉNEZ/FERNÁNDEZ FARRERES, El derecho a la tutela judicial y el recurso de amparo. Una reflexión sobre la jurisprudencia constitucional, Civitas, Madrid, 1995, pp. 70 y ss. 
dio del Derecho Comparado, centrando el análisis únicamente en las respuestas adoptadas por los distintos ordenamientos. No es necesario entrar en el debate doctrinal sobre esta materia, que, como casi siempre, termina por ser farragoso, poco clarificador y de escasa ayuda. Pero acaso sí sea útil dejar constancia de la aproximación de las previsiones jurídicas en torno a dos técnicas a la hora de fijar el elemento tiempo en que deben cumplirse las disposiciones constitucionales programáticas e imperativas.

En algunos textos constitucionales, se señala explícitamente el plazo dentro del cual deben cumplirse sus mandatos. Por el contrario, dado el celo que la clase política tiene de su libertad de configuración, la mayoría no establece un plazo determinado, fijo. Esto hace especialmente interesante el estudio de la figura del plazo razonable.

Cuando un ordenamiento opta por la primera de las técnicas descritas y fija un plazo concreto para el cumplimiento de una exigencia constitucional, que se produzca una inacción legislativa, con las particularidades propias de su definición, durante ese período constituye un claro supuesto de inconstitucionalidad por omisión ${ }^{31}$.

Más problemático y frecuente en la práctica resulta el caso de los textos constitucionales que no fijan dicho plazo. Es evidente, como ya se ha dicho, que el legislador no tiene una libertad absoluta en cuanto a su decisión de actuar o de no hacerlo, puesto que de la misma podría derivar una falta de concreción del texto constitucional con su correspondiente pérdida de fuerza normativa. Por ello, dicha libertad debe moverse dentro de un test de razonabilidad definido en función de las circunstancias y de las exigencias que tenga el precepto en cuestión ${ }^{32}$.

Esta evidencia es especialmente interesante a la luz del carácter social del Estado. Nos parece de capital importancia el estudio de la vinculación de las competencias propias del legislador en actividades prestacionales y un uso concreto, oportuno y eficaz de las mismas, para no incurrir en el desafortunado error de prometer lo que no se puede dar y no disociar las políticas públicas propias de la capacidad de decidir.

Un ejemplo de la determinación del tiempo razonable puede encontrarse en la sentencia 26/1969, de 29 de enero, del Tribunal Constitucional Federal alemán.

$31 \quad$ Tal es el caso del artículo 117.1 de la Ley Fundamental de Bonn, en Alemania, en el que se señala que en el caso de que haya disposiciones contrarias al artículo 3.2 de esta norma, éstas seguirán provisionalmente en vigor hasta que sean adaptadas a dicho artículo, pero nunca más allá del 31 de marzo de 1953.

32 En este sentido se pronuncia el Tribunal Constitucional de Portugal en la sentencia 276/1989, en la que señala que el legislador no posee margen de libertad respecto al cuándo de su intervención, en los casos en los que esa actividad no implique la movilización de especiales recursos o realizar delicadas opciones políticas. 
En ella, con motivo de la problemática suscitada en torno a este tema, se señala que veinte años de retraso es una demora suficiente como para considerar omisiones inconstitucionales ${ }^{33}$.

Según lo hasta ahora expuesto, al hacer un análisis de los distintos ordenamientos, se observa que algunos de ellos atribuyen la conveniencia de señalar el plazo considerado razonable al órgano de justicia constitucional cuando los preceptos constitucionales programáticos (pero de cumplimiento obligatorio) no lo han hecho. Por no detenernos en lo abstracto, podemos señalar el caso del inciso 10 del artículo 436 de la Constitución de Ecuador (2008), que otorga esta facultad a la Corte Constitucional ${ }^{34}$. Este precepto va incluso más allá, puesto que el asigna a la Corte la potestad para que, de manera provisional, dicte la norma o ejecute el acto si transcurrido el plazo el órgano competente aún no lo ha llevado a efecto.

Esta norma guarda cierta similitud con la dictada para el Estado de Chiapas (México), por decreto publicado en el Periódico Oficial del 16 de mayo de $2007^{35}$. En esta misma línea se sitúa el artículo 336 inciso 71 de la Constitución de Venezuela de 1999, al señalar que en caso de inconstitucionalidad por omisión en la generación de normas por parte del poder legislativo nacional, estatal o municipal, la Sala Constitucional del Tribunal Supremo de Justicia «establecerá el plazo y, de ser necesario, los lineamientos de su corrección».

33 Más allá de la bondad o no del tiempo concreto estipulado, que puede ser variable en función del mandato y del compromiso de recursos públicos que éste suponga, lo que interesa de esta sentencia es la resolución del conflicto a través de una aplicación directa de la Norma Suprema.

34 El art. 436 en su inciso 10 señala entre las competencias de la nueva y ahora denominada Corte Constitucional: "declarar la inconstitucionalidad en que incurran las instituciones del Estado o autoridades públicas que por omisión inobserven, en forma total o parcial, los mandatos contenidos en normas constitucionales, dentro del plazo establecido en la Constitución o en el plazo considerado razonable por la Corte Constitucional. Si transcurrido el plazo la omisión persiste, la Corte, de manera provisional, expedirá la norma o ejecutará el acto omitido, de acuerdo con la ley".

35 Néstor Pedro Sagües así lo señala en su artículo Novedades sobre inconstitucionalidad por omisión: la Corte Constitucional de Ecuador como legislador suplente y precario. La norma sancionada para el Estado de Chiapas señala que cuando se considere que el Congreso no ha resuelto alguna ley o decreto y que dicha omisión afecte al debido cumplimiento de la Constitución, el Tribunal Constitucional del Estado intimará al Congreso para que resuelva la omisión en un período de sesiones, y si no lo hace, cuando se trate de leyes cuya expedición está ordenada por la Constitución local o federal, el referido Tribunal Constitucional se pronuncia en torno a la omisión, emitiendo provisionalmente las disposiciones pertinentes, añadiéndose "que dicha legislación estará vigente hasta que el Congreso subsane la omisión legislativa” (art. 56, fracción III de la Constitución del Estado).. 


\section{A MODO DE EPÍLOGO}

Con el título del trabajo, tomado de la célebre novela de Gabriel García Márquez, pretendemos ofrecer al lector una singular paradoja: a pesar de que llevamos cien años de constitucionalismo moderno, la falta de concreción de la norma fundamental deja en una situación de relativa soledad al constituyente frente a la acción de los poderes constituidos, amparándose bajo el principio de libertad de configuración y dirección política.

La inconstitucionalidad por omisión, cuyo estudio hemos enmarcado en los caracteres básicos del Estado constitucional actual, se refiere a la inacción del legislador, durante un tiempo relativamente prolongado, respecto a los encargos que la Constitución le impone, de forma que se impide la eficaz aplicación de ésta y se pone en peligro su normatividad.

Hemos distinguido entre omisiones absolutas (con una ausencia total de un texto legal que desarrolle los preceptos constitucionales) y omisiones relativas (producidas por su deficiente regulación, lo que vulnera el principio de igualdad), al mismo tiempo que hemos ofrecido argumentos que sustentan la naturaleza y existencia de la figura de la inconstitucionalidad por omisión. La necesidad de contraponer el carácter abierto y dirigente de las constituciones modernas y las dificultades que hemos encontrado en la investigación han sido expuestas como condicionantes de los remedios procesales estudiados comparativamente a la luz del Derecho Constitucional Procesal.

En este sentido, nos hemos preguntado por la posibilidad y por la bondad de un control jurídico de los silencios legislativos y, concretamente, de las omisiones inconstitucionales. Salvando las grandes diferencias que puedan existir entre las previsiones que los ordenamientos jurídicos otorguen a la inconstitucionalidad por omisión, hemos señalado las características básicas de las sentencias al respecto.

Posteriormente, y para evitar caer en una crítica irresponsable e infructífera, hemos apostado por una serie de medidas respetando dos elementos que en los estudios jurídicos no siempre son afines: la brevedad del trabajo y el valor añadido que supone la abstracción en los estudios de Derecho Comparado, evitando perdernos en injustificadas observaciones sobre los detalles y respetando en todo momento la libre configuración de los legisladores nacionales.

En este sentido, consideramos que, en virtud de la seguridad jurídica, los textos constitucionales deberían incluir referencias explícitas a la inconstitucionalidad por omisión, ya que el no hacer puede llegar a ser igual de dañino (o incluso más) que la acción positiva. Los órganos de justicia constitucional deberían poder compeler al legislador a integrar la laguna u omisión, pero sin suplir las funciones que el poder constituyente otorgó a aquél.

Una reflexión final que permanece inconclusa dados los axiomas del derecho constitucional es la eterna máxima de "Quis custodiet ipsos custodes?”, es decir, ¿qué 
ocurre cuando la omisión viene del propio órgano de justicia constitucional, quién pospone una sentencia ad infinitum? Parece que una resolución satisfactoria de esta formulación necesita de un enorme esfuerzo de ingeniería constitucional que no dañe la rigidez deseada y deseable de las normas constitucionales y el equilibrio de poderes.

Nos gustaría terminar con la misma perplejidad con la que empezamos el trabajo, aludiendo a una nueva y moderada forma de uso y distribución del poder. Al fin y al cabo, los poderes públicos no han sido respetuosos, en general, con el mandato de organización racional de la vida social que les incumbe por la voluntad expresa del Pueblo soberano. Frente a él, existen movimientos oscilantes que lo desplazan y consiguen un centro de gravedad cortoplacista en los poderes constituidos que, lejos de asegurar el principio democrático, levantan un dique entre Constitución y ley.

No queda más remedio que protegernos de este torpe 'presentismo', es decir, de la incapacidad para salir de lo inmediato y lo simple a través de la reflexión crítica y el ejemplo. Y, en la medida de nuestras posibilidades, hemos procurado que de ello sea producto el trabajo que el lector tiene en sus manos.

Hoy corren tiempos que banalizan, en interés de muchos políticos, la diferencia que media entre la acción política y el Derecho como instrumento procesal de garantía para los ciudadanos. Y es que no debemos estar dispuestos a convertirnos, como diría Pocock, en mero material pasivo de alguien eternamente ansioso de inventar por nosotros.

\section{REFERENCIAS}

ARAGÓN REYES, Manuel. "Sobre las nociones de supremacía y supralegalidad constitucional”, Revista de Estudios Políticos, núm. 50, 1986, pp. 9 y ss.

El control como elemento inseparable del concepto de constitución, «Revista Española de Derecho Constitucional», núm. 19, 1987, pp. 17 y ss.

BRUST, Léo. La sentencia constitucional en Brasil, Universidad de Salamanca, 2011.

FERNÁNDEZ RODRÍGUEZ, José J. "La inconstitucionalidad por omisión", Revista Vasca de Administración Pública, núm. 39, 1994.

La inconstitucionalidad por omisión. Teoría General. Derecho Comparado. El caso español, Civitas, Madrid, 1998.

FERNÁNDEZ SEGADO, Francisco. "Sistemas de protección judicial de los derechos fundamentales", Revista General del Derecho, núm. 591, 1993.

GARCÍA DE ENTERRÍA, Eduardo. La Constitución como norma y el Tribunal Constitucional, Civitas, Madrid, 1985 ( $3^{\mathrm{a}}$ ed.). 
. "Un paso importante para el desarrollo de nuestra justicia constitucional: la doctrina prospectiva de las leyes inconstitucionales", Revista Española de Derecho Administrativo, núm. 61, 1989, pp. 5 y ss.

GARCÍA PELAYO, Manuel. Derecho Constitucional Comparado, Alianza, Madrid, 1984.

GOMES CANOTILHNO, José J. Constituçao dirigente e vinculaçã dolegislador. Constributo para a compreenção das normas constitucionais programáticas, Coimbra Editora, 1982.

. "Tomemos a seério o silêncio dos Poderes Públicos. O directo à emanaçao de normas jurídicas e a protecçao judicial contra os omissoes normativas", As garantias do cidadão na justiça, Saraiva, São Paulo, 1993, pp. 309 y ss. . “¿Revisar la/o romper con la Constitución dirigente? Defensa de un constitucionalismo moralmente reflexivo", Revista Española de Derecho Constitucional, núm. 43, 1995, pp. 9 y ss.

MARTÍN DE LA VEGA, Augusto. La sentencia constitucional en Italia, Centro de Estudios Constitucionales, Madrid, 2003.

MARTÍNEZ ZORRILLA, David. Metodología jurídica y argumentación, Marcial Pons, Madrid, 2010.

RUBIO LLORENTE, Francisco. La forma del Poder: estudios sobre la Constitución, Centro de Estudios Constitucionales, Madrid, 1993.

SAGÜES, Néstor Pedro. Novedades sobre la inconstitucionalidad por omisión: la Corte Constitucional de Ecuador como legislador suplente y precario, en «Estudios Constitucionales», Talca, año 7, núm. 2, 2009.

VILLAVERDE MENÉNDEZ, Ignacio. La inconstitucionalidad por omisión, McGraw-Hill, Madrid, 1997. 